\title{
Calculation method of main cable saddle of suspension bridge based
}

\section{on energy method}

\author{
Juan Luan ${ }^{\mathrm{a}}$, Xianwu Hao ${ }^{\mathrm{b}}$, Ruifang Duan ${ }^{\mathrm{c}}$ \\ ${ }^{1}$ School of Highway Chang'an university, Xi'an 710064 \\ ${ }^{2}$ Shaanxi College of Communication Technology, Xi'an 710018 \\ a20342862@qq.com, b158375689@qq.com
}

Key words: suspension bridge; energy method; saddle pushing; tower top displacement; pushing force

\begin{abstract}
In order to ensure that the main tower of the suspension bridge is always in a safe state during the lifting process of the stiffening girder, the reasonable determination of the main cable saddle push and push stage is very important. Based on the energy principle, the Rayleigh-Ritz method is used to derive the formula for calculating the maximum allowable deviation of the main tower. Research results show that The results calculated by the formula are $7 \%$ different from the finite element calculation results.
\end{abstract}

\section{Introduction}

In suspension bridge construction, with the continuous lifting of the stiffening girder, the cable force in the middle and side span is more and more unbalanced. By setting a certain amount of pre bias to the main cable saddle, it will be free to slide to the equilibrium position under the action of unbalanced cable force. However, due to the factors such as construction safety and controllability, it is not allowed to slide freely. In the actual construction, by taking appropriate measures to carry out artificial and controllable multiple push. Therefore, the main cable saddle is the main factor of the relationship between the top push time and the amount of the top push is the main factor for the safety of the main tower ${ }^{[1]}$. Three dimensional finite element model is used by He Wei et al ${ }^{[2]}$. Reasonable calculation mode and pre equilibrium condition of saddle offset are studied by Qi Dongchun et $\mathrm{al}^{[3]}$. The calculation control principle and the calculation theory of the allowable deviation of the top of the tower are determined. suspension bridge pylon section no tensile stress and tensile stress is not allowed to overrun 2 kinds of strength under the condition of the main tower deviation are analyzed by Sun Shengjiang et $\mathrm{al}^{[4]}$. The maximum displacement of pier top is studied by Cheng Xiangyun ${ }^{[5]}$ and Bai Qingxia ${ }^{[6]}$ based on the principle of minimum potential energy, using Rayleigh-Ritz method to solve the problem of geometric nonlinear analysis of high bridge piers. the

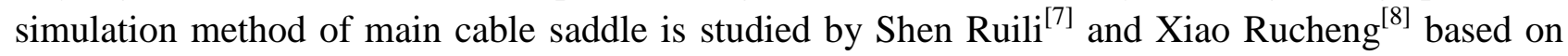
the finite element method. A new method for the refinement of the cable saddle push fine simulation is presented by LI Zhizhong ${ }^{[9]}$, which studies the comparison of different cable saddle models and the safety factor of the main cables.

\section{Formula derivation}

The mechanical model of the main tower suspension bridge can be simplified into a cantilever beam with uniform cross section and combined action of horizontal force of the main tower $\mathrm{H}$ (unbalanced cable force in horizontal direction), Vertical force $\mathrm{N}$ (upside structure support) and the weight of main tower q. 
The approximate function of the longitudinal deviation of the main tower

$$
y=\alpha \cos \frac{\pi x}{2 l}
$$

Formula (1) to satisfy the boundary conditions, A is the maximum allowable deviation to be determined of the main tower in the formula.

The total potential energy of the structure can be expressed as $\Pi$

$$
\begin{gathered}
\Pi=\frac{E I}{2} \int_{0}^{l}\left(y^{\prime \prime}\right)^{2} \mathrm{dx}-\frac{1}{2} N \int_{0}^{l}\left(y^{\prime}\right)^{2} \mathrm{dx}-q \int_{0}^{l} \Delta(x) \mathrm{dx}-H a \\
\int_{0}^{l} \Delta(x) \mathrm{dx} \approx \frac{l}{3} \Delta_{\max } \\
\Delta_{\max } \approx \frac{1}{2} \int_{0}^{l}\left(y^{\prime}\right)^{2} \mathrm{dx}
\end{gathered}
$$

Where $\triangle_{\max }$ is Maximum vertical displacement of the top of the tower after bending deformation; $\triangle(x)$ is The vertical displacement function based on the curve of the amplitude of $\triangle_{\max } ; E$ is elastic modulus of main tower; $I$ is Inertia moment of main tower section; $l$ is the height of main tower; $q=s \gamma, \mathrm{s}$ is the Sectional area of main tower; $\gamma$ is the density of concrete.

\section{Example verification}

The span distribution of a suspension bridge is $166 \mathrm{~m}+628 \mathrm{~m}+166 \mathrm{M}$. The design of the main cable span ratio is $1 / 10$. The left and right tower are different height, the higher is $153.5 \mathrm{~m}$, the other is $138.5 \mathrm{~m}$.

In calculating the maximum allowable displacement of the top of the tower, the height of main tower is the average height of the high and the low. Vertical force $\mathrm{N}$ in the bare tower is mainly refers to the gravity of the main cable saddle. The specific parameters are shown in Table 2.

Table 1 Parameters of real bridge

\begin{tabular}{ccccccc}
\hline$E /\left(\mathrm{kN} \cdot \mathrm{m}^{-2}\right)$ & $I / \mathrm{m}^{4}$ & $S / \mathrm{m}^{2}$ & $l / \mathrm{m}$ & $\gamma /\left(\mathrm{kN} \cdot \mathrm{m}^{-3}\right)$ & $H / \mathrm{kN}$ & $N / \mathrm{kN}$ \\
\hline $3.45 \times 10^{7}$ & $3.24 \times 10^{2}$ & 41.86 & 146 & 26 & 1350 & 731 \\
\hline
\end{tabular}

Finite element method calculation of the top of the tower's maximum horizontal deflection A and formula calculation results are shown in Table 3.

Table 2 Horizontal displacement of top tower with different calculation methods

\begin{tabular}{cccc}
\hline \multirow{2}{*}{ Program } & Without the effect of & \multicolumn{2}{c}{$P-\Delta$} \\
\cline { 3 - 4 } & $P-\Delta$ & energy method & finite method \\
\hline$a / m$ & 0.123 & 0.129 & 0.133
\end{tabular}

According to the optimization principle of saddle pushing the main cable, to optimize bridge pushing volume and thrust force are shown in table 4. Figure 1, 2 only consider the bottom of the tower stress push scheme. 
Table 3 Pushing optimization scheme of main cable saddle of suspension bridge

\begin{tabular}{cccccc}
\hline \multirow{2}{*}{ Push stage } & \multicolumn{2}{c}{ Left } & \multicolumn{2}{c}{ Right } & \\
\cline { 2 - 5 } & $\begin{array}{c}\text { Push } \\
\text { amount } \\
/ \mathrm{mm}\end{array}$ & $\begin{array}{c}\text { Push } \\
\text { force/kN }\end{array}$ & $\begin{array}{c}\text { Push } \\
\text { amount } \\
/ \mathrm{mm}\end{array}$ & $\begin{array}{c}\text { Push } \\
\text { force } \\
/ \mathrm{kN}\end{array}$ & \\
\hline 1st push & 88.1 & 550.3 & 89.1 & 543.3 & After mid-span No.1 steel girder lifting \\
2nd push & 96.5 & 671.2 & 97.9 & 664.5 & After mid-span No.4 steel girder lifting \\
3rd & 97.4 & 873.5 & 99.7 & 861.4 & After mid-span No.9 steel girder lifting \\
4th & 100.9 & 1175.6 & 104.2 & 1158.9 & After mid-span No.17 steel girder lifting \\
5th & 102.6 & 1570.7 & 106.5 & 1548.5 & After mid-span No.29 steel girder lifting \\
6th & 103.6 & 2076.2 & 107.1 & 2049.4 & After mid-span No.53 steel girder lifting \\
7th & 110.9 & 2683.5 & 95.5 & 2648.8 & After pavement \\
\hline
\end{tabular}

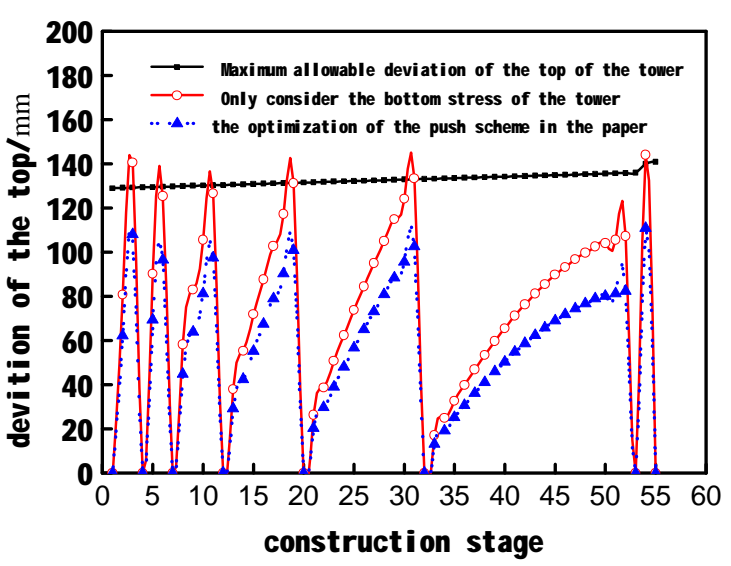

Fig. 1 Comparison of saddle pushing scheme of left bank

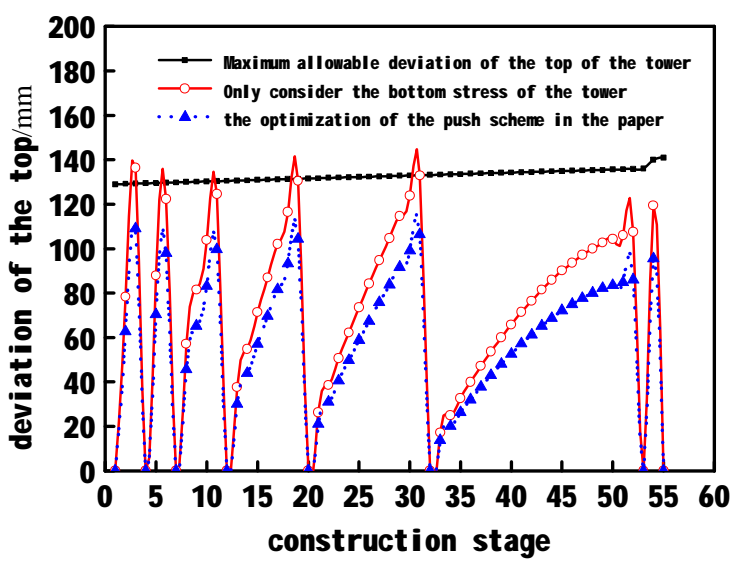

Fig.2 Comparison of saddle pushing scheme of right bank

According to the analysis of table 4 and figure 1 and figure 2, we can know that the top pushing scheme by controlling the deviation of the top and the bottom of the tower is more in line with the requirements of the actual main cable saddle. From the consolidation and without pushing, optimizing the push scheme of the paper, considering the $\mathrm{P}$ effect or not which four conditions are analyzed to the top of the tower.

Analysis of the left and right bank is shown in Figure 3 and Figure 4.

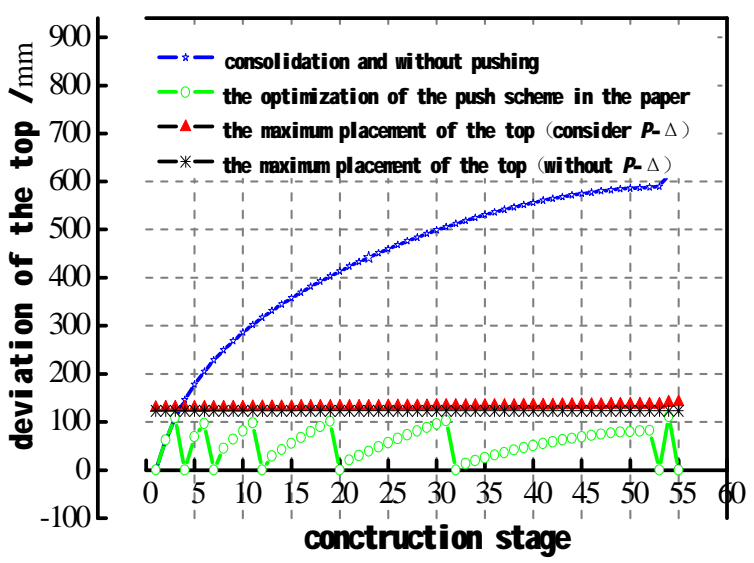

Fig.3 Tower displacement of left bank with construction steps

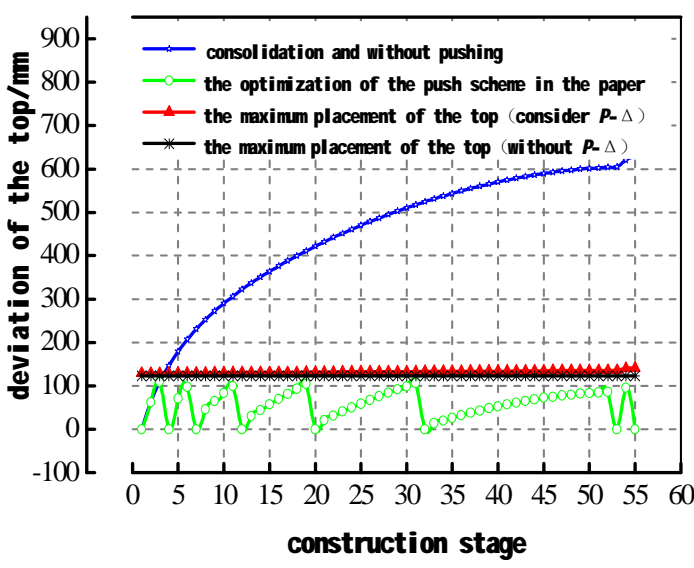

fig.4 Tower displacement of right bank with construction steps

From Figure 3 and Figure 4 shows that, in the main cable saddle consolidation and pushing 
condition, with the stiffening girder hoisting, side span unbalanced force is more and more, resulting in main tower to the cross direction deviation is more and more big, when the tower exceeds maximum allowable displacement will endanger the safety of main tower.

Analysis bottom stress of the construction stage of the left and right bank is shown in Figure 6 and Figure 7.

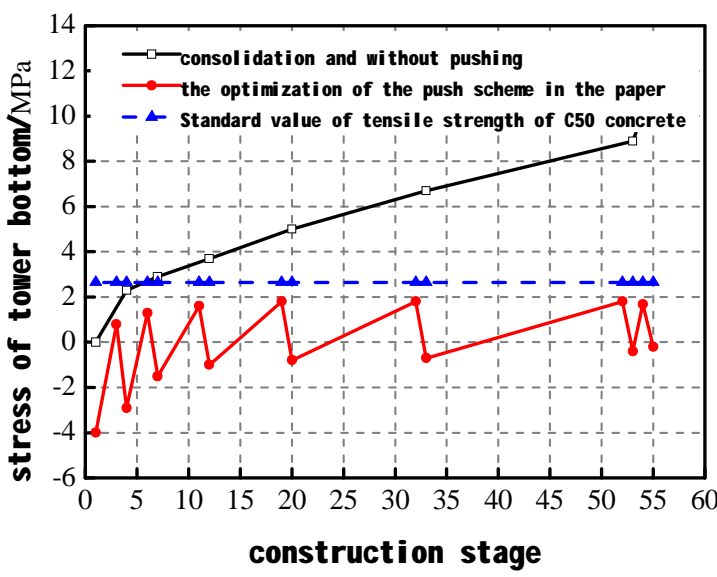

Fig.5 Tower bottom stress of left bank with construction stages

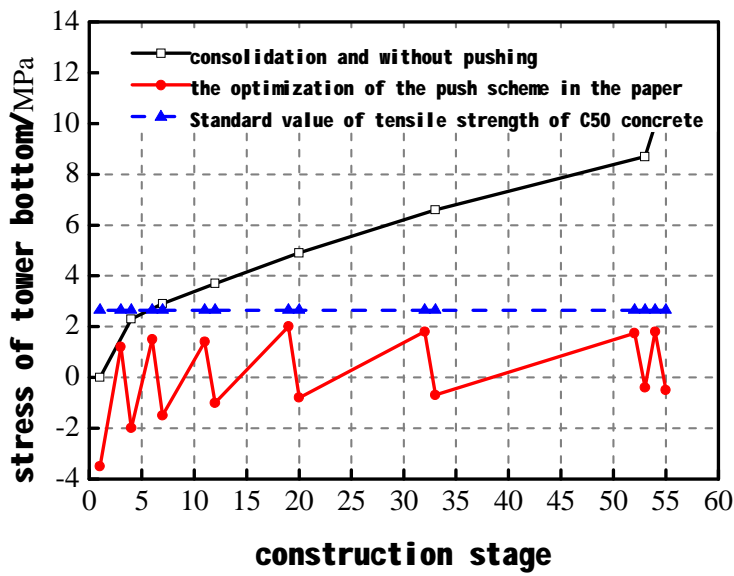

Fig.6 Tower bottom stress of right bank with construction stages

From Figure 5 and figure 6 analysis shows that, in the main cable saddle consolidation and pushing the, main cable saddle at the bottom of the tower stress with the construction stage is more and more big, when the value exceeds the tensile strength of concrete at the bottom of the tower concrete cracking, endanger the safety of the main tower.

\section{Conclusions}

(1) In the bare tower, based on energy method, the derived formula to calculate the top maximum deviation with the finite element method calculation results between $3.4 \%$

(2) When calculating the maximum deviation of the top of the tower, the deviation is $4.6 \%$ which is very small, if the maximum allowable deviation of the top of the column can be ignored.

(3) In a bare tower at the top of the largest allowable deviation is the smallest, with stiffening girder of continuous lifting, main tower subjected to vertical force is bigger and bigger, leading to the main tower of the maximum allowable displacement increases gradually to $19.9 \%$.

\section{References}

[1] Qian Dongsheng, Chen Renfu. Design and construction of long span suspension bridges [M], Chengdu: Southwest Jiaotong University Press, 1999,15-16

[2] HE W, XIANG Y Q, XU X. Frequent short steps saddle pushing principle in suspension bridge construction[J]. Journal of Zhejiang University(Engineering Science), 2007，41(1):134-138.

[3] QI D C, WANG C J, SHEN R L, et al. Saddle pushing analysis in suspension bridge construction $[\mathrm{J}]$. Engineering Science, 2010, 12(7) :68-73.

[4] SUN S J, JIANG J. Analysis of tower's allowable displacement and main saddle's pushing of suspension bridge [J] . Highway, 2007, 51(10): 54-57.

[5] SHEN R L. Calculation methods for design and erection of cable curve of suspension bridge [J] . Journal of Civil Engineering, 1996, 29(2):3-9.

[6] XIAO R C, XIANG H F. Research on the structural analysis theory and special program of long-span suspension bridge $[\mathrm{J}]$. China Journal of Highway and Transport, 1998, 
11(4) :42-50.

[7] LI Z Z, JIANG J S, LIN Z M. Saddle pushing simulation method and example analysis of main cable of suspension bridge $[\mathrm{J}]$. Highway, 2012, $56(12): 48-51$.

[8] WANG X L, YUE Z M. Analysis of tower top displacement control values of long span suspension bridge $[\mathrm{J}]$. Bridge Construction, 2003, 33(6): 38-40.

[9] ZHANG K P, ZHANG A P, ZHU Y C. Pushing analysis and pushing plan optimization for suspension across main saddle $[\mathrm{J}]$. Transportation Science \& Technology 2010, 35(5):7-9. 